\title{
Numerical Modeling of Stress Disturbance Characteristics during Tunnel Excavation
}

\author{
Zeqi Zhu, ${ }^{1,2}$ Qian Sheng,, ${ }^{1,2}$ Yumin Zhang, ${ }^{3}$ and Shiwei Liu $\mathbb{D I D}^{1,4}$ \\ ${ }^{1}$ State Key Laboratory of Geomechanics and Geotechnical Engineering, Institute of Rock and Soil Mechanics, \\ Chinese Academy of Sciences, Wuhan 430071, China \\ ${ }^{2}$ School of Engineering Science, University of Chinese Academy of Sciences, Beijing 10049, China \\ ${ }^{3}$ School of Resources and Environment, North China University of Water Resources and Electric Power, \\ Zhengzhou 450046, China \\ ${ }^{4}$ College of Water Conservancy and Hydropower, Hebei University of Engineering, Handan, Hebei 056001, China
}

Correspondence should be addressed to Shiwei Liu; liu1989shiwei@163.com

Received 3 December 2019; Revised 14 March 2020; Accepted 1 April 2020; Published 28 April 2020

Academic Editor: Aniello Riccio

Copyright (c) 2020 Zeqi Zhu et al. This is an open access article distributed under the Creative Commons Attribution License, which permits unrestricted use, distribution, and reproduction in any medium, provided the original work is properly cited.

\begin{abstract}
The stress state and principal stress axis changes of the stress-field tensor are analyzed during the advancement of a tunnel face on the basis of a given case study of the Jinping II Hydropower Station in China. First, the prevailing pole diagram in geology is used to illustrate the rotation of the stress axes as the tunnel face advances. The results show that the orientation adjustments of principal stresses in different positions near the tunnel boundary share common characteristics. The major and minor principal stress axes ahead of the tunnel face will rotate to intersect with the excavation surface at an angle, with the intermediate principal stress axis being almost parallel to the excavation surface. Furthermore, the stress triaxiality that is commonly used to indicate the deformation and damage of metal materials is introduced to describe the stress state change of the excavation-induced stress. The stress triaxiality is found to represent the stress state change due to the variation in both the magnitude and orientation of the stress-field tensor. According to the physical meaning and the change law of the stress triaxiality, stress disturbance during tunnel excavation can be divided into four stages, and the stress disturbance zone is divided into a strong disturbance zone and a weak disturbance zone. The disturbance characteristics of different stages and the distribution patterns of various zones are analyzed, which may be useful for practical application in the design and construction of rock tunnels.
\end{abstract}

\section{Introduction}

It is widely known that tunnel excavation can lead to stress changes and possible damage ahead of a tunnel face. Increased attention has been given to this issue during rock mechanics research and underground excavation projects [1-6]. Excavation-induced stress is commonly described by analyzing the progressive development and evolution of the near-field stress distribution and stress paths during the advancement of a tunnel face. Many researchers have carried out studies on stress disturbance during tunnel excavation by means of various methods such as theoretical analysis and field tests. The main representative studies are the Underground Research Laboratory (URL) of Atomic Energy of
Canada Limited (AECL) (1989-1996), which carried out a large number of field tests and monitoring work for Lac du Bonnet granite $[7,8]$; the Swedish Nuclear Fuel and Waste Management Company (SKB), which conducted a variety of tests and analysis work based on the Hard Rock Laboratory on the island Äspö of southeast Sweden [9]. In the zone of excavation disturbance experiments (ZEDEX) conducted by SKB (Sweden), ANDRA (France) and UK Nirex (UK), the research suggests that the damage zone is in the proximity of a tunnel boundary (referred to as the near-field), where irreversible changes of rock mass properties occur. Moving away from the tunnel boundary, rock mass properties in the disturbance zone (relatively, in the far-field) undergo little change and most can be recovered [10]. In China, in regard 
to the deeply buried diversion tunnels of the Jinping II Hydropower Station, Jiang et al. [11] and Feng et al. [6] performed comprehensive in situ observation tests and dynamic feedback analysis to evaluate the cracking process and stability of surrounding rock; Liu et al. [12] carried out research on the tunnel face effect due to stress changes by monitoring the stress in deeply buried diversion tunnels during TBM tunneling and used the results to determine the range of the damage zone.

The distribution and redistribution of excavation-induced stress involves not only the change in stress magnitudes but also the rotation of the principal stress axes as a tunnel excavation is approached. However, the rotation of principal stress axes is normally neglected as tunneling projects continue to progress into deeper and more complex geological environments. A wealth of geotechnical tests show that pure principal stress axis rotation (with no change in magnitudes of principal stresses) can lead to obvious plastic deformation [13]. In recent years, soil constitutive models that consider the principal stress axes rotation, as well as its effect on deformation, have been developed [14]. However, few studies on the principal stress axes rotation of rock mass, especially on rotation due to excavation disturbance, were found. Carter [15] and Germanovich and Dyskin [16] have demonstrated that the microfracturing process, related to damage and rock strength degradation/ failure, is largely controlled by the deviatoric stresses and the orientation of the principal stress axes by analyzing the excavation-disturbed near-field stress zone. Eberhardt [17] analyzed the change in principal stress values and the characteristics of principal stress axes rotation ahead of a tunnel face in circular tunnels during excavation under different geostress conditions. Generally, describing the three-dimensional space change of principal stress orientation following rock tunnel excavation is difficult using a two-dimensional analysis method or graphic representation method. In addition, conventional mechanical indexes such as the average normal stress, equivalent shear stress, and rod parameter are extensively used to analyze the excavationinduced stress ahead of the tunnel face, but these stress indexes do not consider the principal stress axes rotation and its effect, especially the stress state change of the excavationinduced stress.

This paper develops a numerical model of diversion tunnels for the Jinping II Hydropower Station to simulate the rotation of principal stress axes and the change in stress state ahead of the tunnel face by means of finite difference modeling. The pole diagrams prevailing in geology and the stress triaxiality commonly used to indicate the deformation and damage of metal materials are introduced to carry out the initial study on the three-dimensional characteristics and distribution pattern of stress disturbance during the advancement of the tunnel face.

\section{Engineering Case and Numerical Model}

The Jinping II Hydropower Station is located in the winding region of the Jinping Bend of theYalong River in Sichuan Province, China, with approximately a $310 \mathrm{~m}$ water head along a $150 \mathrm{~km}$ river section. As a diversion-type power station, four diversion tunnels were excavated to provide a $4800 \mathrm{MW}$ installed capacity. The four tunnels are the key project simply because they are buried deep, with an average length of approximately $16.67 \mathrm{~km}$, an excavation diameter $D$ of approximately $13 \mathrm{~m}$, a maximum buried depth of approximately $2525 \mathrm{~m}$, and an overburden rock depth of generally 1500-2000 m. Therefore, based on the literature and measured geostress and rock mass mechanical parameters [6], this paper takes the diversion tunnel excavation as an example to research stress disturbance near and ahead of the tunnel face. Furthermore, only one of the four diversion tunnels was selected to establish the numerical model for the sake of calculative simplification.

The Chainage $15+700$ section of No. 2\# tunnel is selected as a reference section, with a $100 \mathrm{~m}$ long tunnel segment near the reference section as a study case. This segment is buried by $1100 \mathrm{~m}$ of thick overburden rock, with a gravity stress of approximately $29.2 \mathrm{MPa}$. The major principal stress $\sigma_{1}$ is assumed to be parallel to the tunnel axis, and $\sigma_{1}$ is 1.3 times as large as the gravity stress, namely, approximately $38.0 \mathrm{MPa}$. The intermediate principal stress $\sigma_{2}$ is 1.2 times as large as the gravity stress, namely, approximately $34.8 \mathrm{MPa}$, forming an angle of $22.5^{\circ}$ with the horizontal plane. The minor principal stress $\sigma_{3}$ is the same as the gravity stress, namely, approximately 29.2 MPa, forming an angle of $67.5^{\circ}$ with the horizontal plane. The corresponding normal and shear stresses calculated by the elastic mechanical formula are applied on the boundary of the numerical model to meet the magnitudes and directions of the primary in situ stress field.

The numerical model and the $X, Y$, and $Z$ coordinate systems are established, as shown in Figure 1, with axis $Z$ along the tunnel centerline, axis $X$ normal to axis $Z$ in the horizontal plane, and axis $Y$ as vertical. The total model size is $130 \mathrm{~m}$ along axis $X, 130 \mathrm{~m}$ along axis $Y$, and $100 \mathrm{~m}$ along axis $Z$, with 16,650 elements and 173,316 nodes. The reference section selected is at $Z=60 \mathrm{~m}$, and the schematic advancing of the tunnel face is shown in Figure 2. The cyclical footage is set to be $2 \mathrm{~m}$ in the important study region $(Z=40-60 \mathrm{~m})$ and $5 \mathrm{~m}$ in the other regions to better reveal the stress changes and principal stress axes rotation with the advancement of the tunnel face.

The tunnel size is shown in Figure 3 and some monitoring points are set at typical positions such as the tunnel roof and tunnel wall, both on the tunnel boundary and along a parallel line $1 \mathrm{~m}$ into the rock mass in the reference section $(Z=60 \mathrm{~m})$. The Mohr-Coulomb model is used and Table 1 provides the material properties used in the elastoplastic model.

\section{Principal Stress Axes Rotation ahead of an Advancing Tunnel Face}

The typical principal stress orientation vectors of monitoring point $A$ in the reference section are shown in Figure 4 during the advancement of the tunnel face. The direction of the principal stresses experiences rotations at different degrees when the tunnel face is far from, before, on, and behind the 


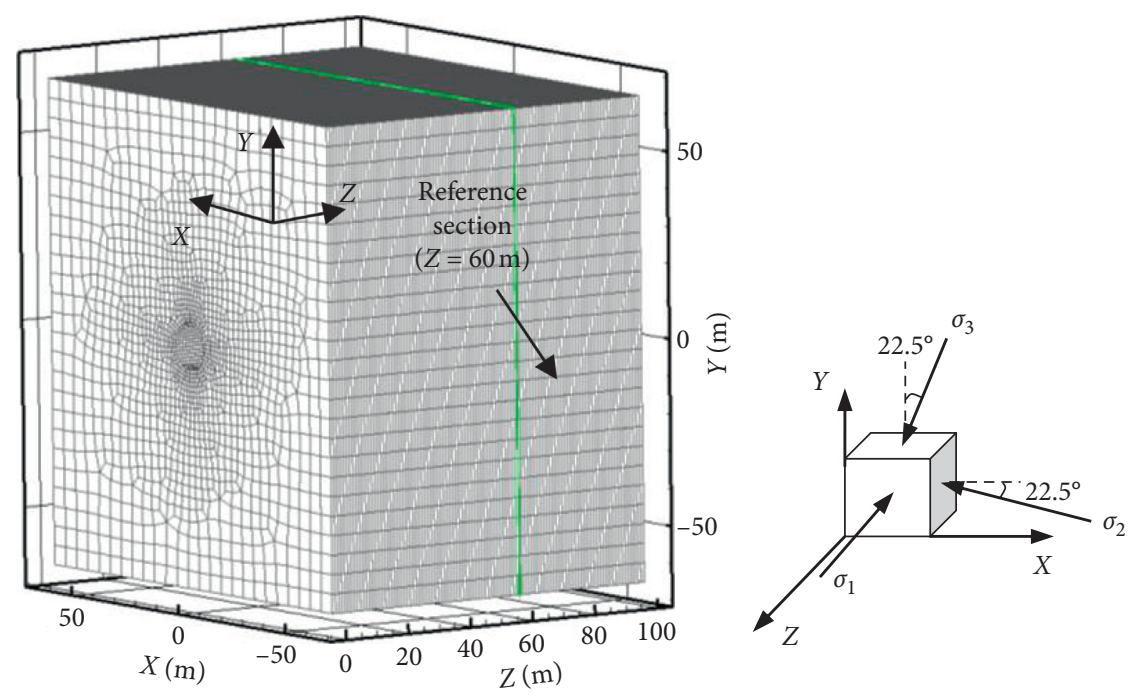

FIgURE 1: Three-dimensional finite difference mesh, model geometry, and in situ stress-field.

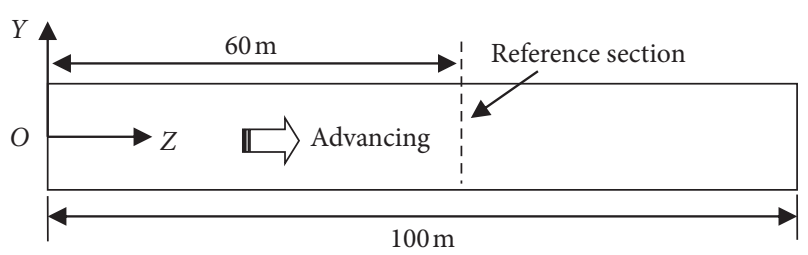

FIGURE 2: Schematic advancing of the tunnel face.

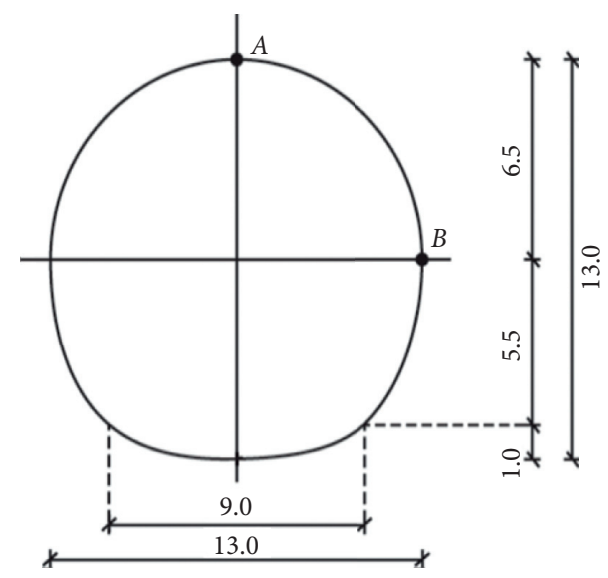

FIGURE 3: Tunnel geometry and layout of monitoring points in the reference section $(Z=60 \mathrm{~m})$ (unit: $\mathrm{m})$.

TABLE 1: Finite difference mesh input parameters used in the threedimensional tunnel model.

\begin{tabular}{lc}
\hline Model input parameter & Value \\
\hline Density, $\rho$ & $2750 \mathrm{~kg} / \mathrm{m}^{3}$ \\
Young's modulus, E & $30.0 \mathrm{GPa}$ \\
Poisson's ratio, $v$ & 0.20 \\
Intact cohesion, $c$ & $2.0 \mathrm{MPa}$ \\
Intact friction angle, $\phi$ & $55.0^{\circ}$ \\
Tensile strength, $\sigma_{t}$ & $1.0 \mathrm{MPa}$ \\
\hline
\end{tabular}

reference section. The stress tensor in the tunnel roof is generally unchanged in comparison to its initial in situ state when the tunnel face is far from the reference section (Figure 4(a)). As the tunnel face approaches the reference section, the principal stress axes in the tunnel roof rotate significantly from the initial in situ condition (Figure 4(c)). Then, the principal stress direction vectors are readjusted to be approximately parallel to the coordination of the numerical model after the tunnel face passes through the reference section, with the $\sigma_{1}$ stress axis rotated to point in the $X$-axis direction.

However, illustrating the rotation process of the principal stress axes during tunnel excavation in a precise and intuitive way using the direction vectors in Figure 4 is difficult. Thus, the pole diagram is introduced to represent the principal stress orientation and its rotational change. According to the geographical orientation of the actual project, the $X, Y$, and $Z$ axes of the coordinate system in Figure 1 point to the north, vertical, and east, respectively. At the same time, $\eta$ and $\xi$ are assumed to represent the inclination and dip of a principal stress axis, as shown in Figure 5. The angles between the principal stress axis and $X$, $Y$, and $Z$ are denoted by $\alpha, \beta$, and $\gamma$, respectively. In terms of the spatial relation, $\eta$ and $\xi$ can be expressed by $\alpha, \beta$, and $\gamma$ as follows:

$$
\left.\begin{array}{c}
\eta=\arctan \left(\frac{\cos \gamma}{\cos \alpha}\right), \quad \text { if } \cos \alpha>0, \\
\eta=90^{\circ}, \quad \text { if } \cos \alpha=0, \cos \gamma>0, \\
\eta=270^{\circ}, \quad \text { if } \cos \alpha=0, \cos \gamma<0, \\
\eta=\arctan \left(\frac{\cos \gamma}{\cos \alpha}\right)+180^{\circ}, \quad \text { if } \cos \alpha<0,
\end{array}\right\}
$$




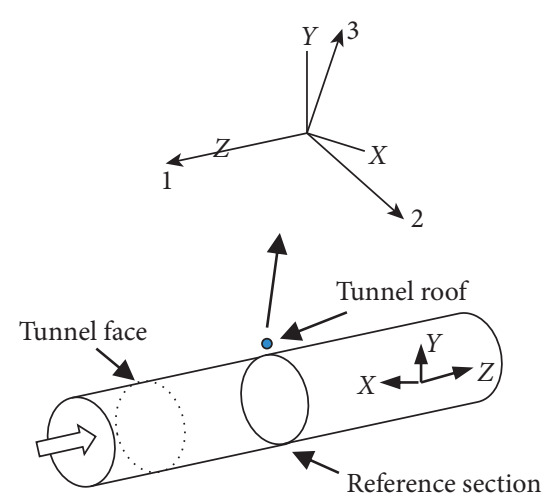

(a)

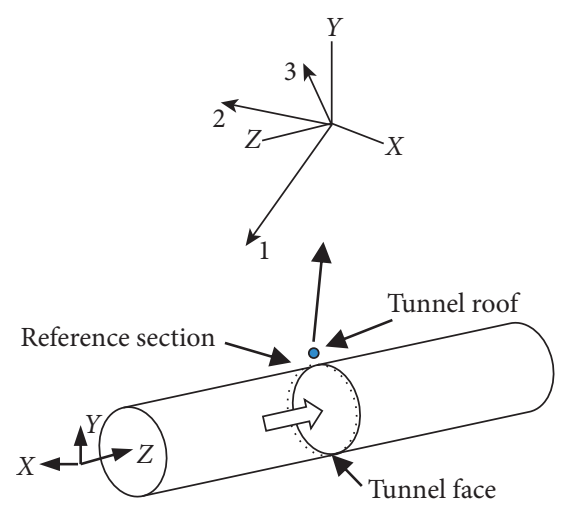

(c)

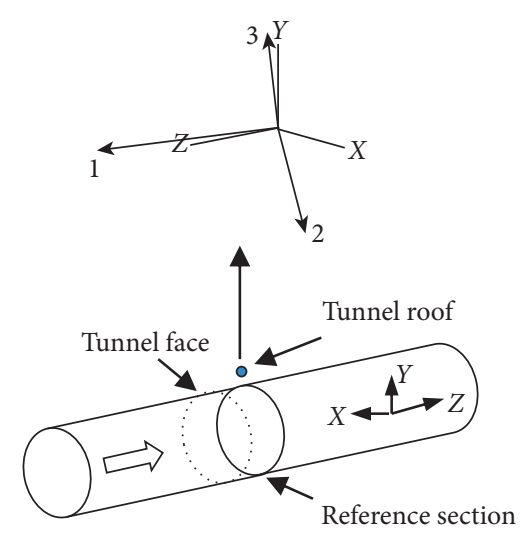

(b)

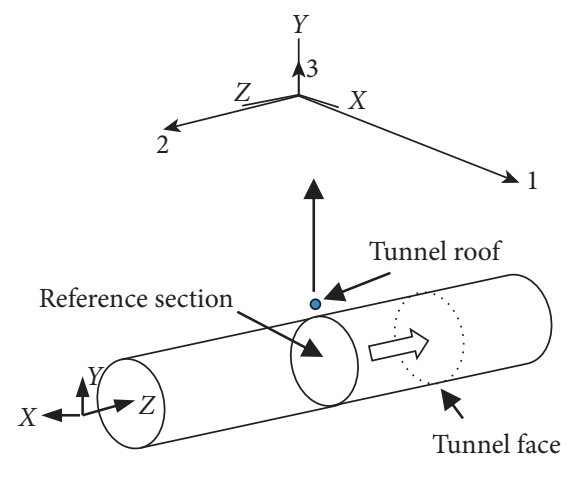

(d)

Figure 4: Principal stress orientation vectors of the tunnel roof at different advancing stages.(a) Tunnel face far from the reference section. (b) Tunnel face before the reference section. (c) Tunnel face on the reference section. (d) Tunnel face behind the reference section.

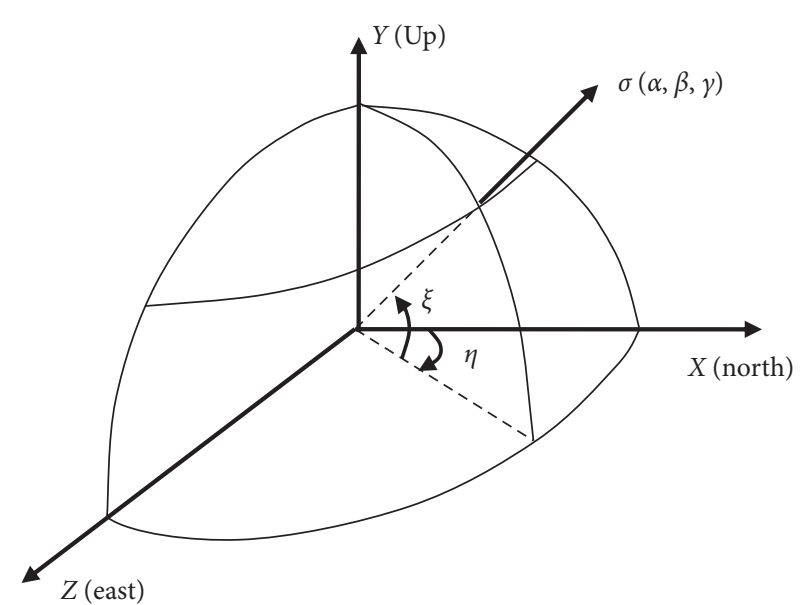

FIGURE 5: The principal stress axis represented in geographic coordinates and computational coordinates.

In the finite difference numerical calculation, three direction $\operatorname{cosines} \cos \alpha, \cos \beta$, and $\cos \gamma$ are used to describe the direction of principal stress. Through equations (1) and (2), the direction of principal stress can be described in the twodimensional pole diagram by the two direction indexes of inclination and dip. Using this method, information about the principal stress axes at monitoring points is transformed into pole diagrams as the tunnel face moves from $0 \mathrm{~m}$ to $60 \mathrm{~m}$, which can reflect the change process of principal stress axes in some detail.

The relationship between geographic coordinates and computational coordinates in Figure 5 shows that the diversion tunnel axis extends from west to east. The pole diagrams of monitoring point A and B are shown in Figure 6 during the tunneling period from beginning to reference section. Let "WF" denote the position of the working face. For monitoring point $\mathrm{A}$, the inclination of the $\sigma_{1}$ stress axis, which points to the tunnel axis at $\mathrm{WF}=0$, rotates gradually from $0^{\circ}$ to approximately $60^{\circ}$ at which the $\sigma_{1}$ stress axis cuts the tunnel axis when $\mathrm{WF}=50 \mathrm{~m}$ and decreases rapidly to approximately $0^{\circ}$ at $\mathrm{WF}=60 \mathrm{~m}$. From $\mathrm{WF}=0$ to $\mathrm{WF}=60 \mathrm{~m}$, the dip angle $\xi$ of the $\sigma_{1}$ stress axis increases constantly from $0^{\circ}$ to approximately $34^{\circ}$. The inclination of the $\sigma_{3}$ stress axis, which is perpendicular to the tunnel axis at $\mathrm{WF}=0$, rotates gradually from $90^{\circ}$ to approximately $0^{\circ}$ at $\mathrm{WF}=60 \mathrm{~m}$, while the dip angle $\xi$ of the $\sigma_{3}$ stress axis changes slightly from $67.5^{\circ}(\mathrm{WF}=0)$ to approximately $55^{\circ}(\mathrm{WF}=60 \mathrm{~m})$. Generally, for the tunnel roof at WF $=60 \mathrm{~m}$, the inclination of the major and minor principal stress axes are approximately parallel to the tunnel axis, and $\xi$ of the major and minor principal stress axes are approximately $34^{\circ}$ and $55^{\circ}$, respectively. The inclination of the $\sigma_{2}$ stress axis is basically normal to the tunnel axis, with $\xi$ equal to approximately $0^{\circ}$. 


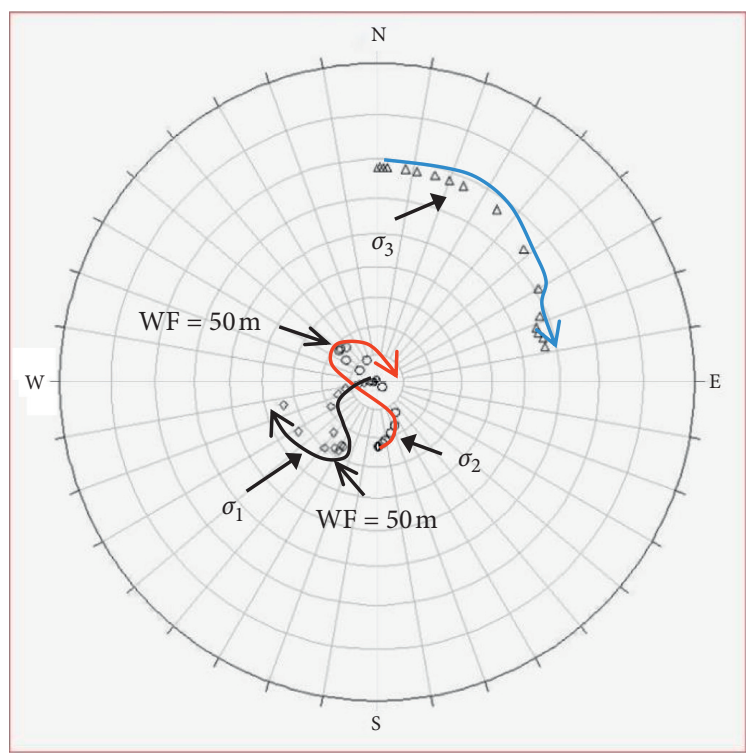

(a)

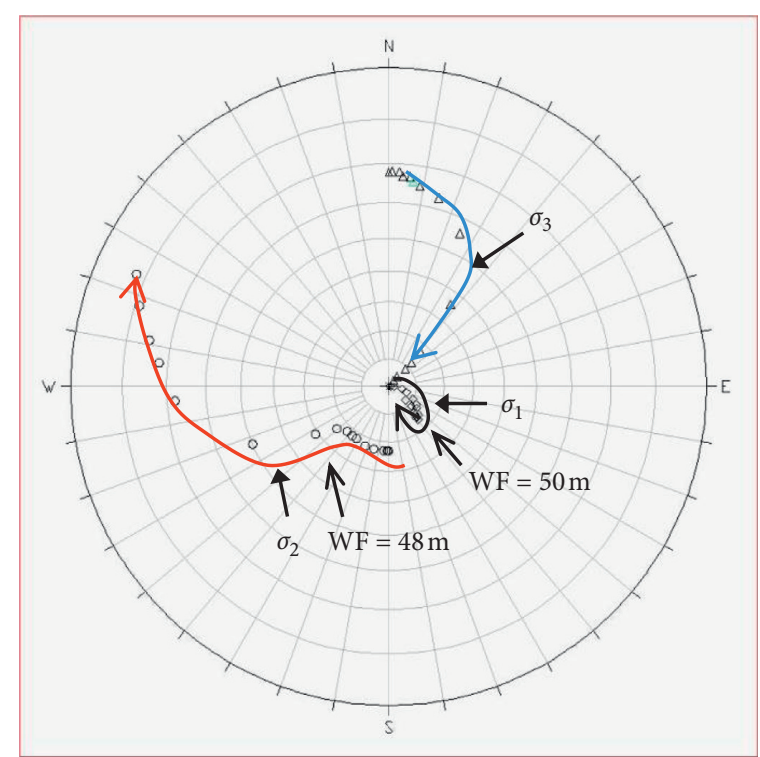

(b)

Figure 6: Pole diagrams of principal stress axes of monitoring points as the tunnel face approaches from $\mathrm{WF}=0$ to $\mathrm{WF}=60 \mathrm{~m}$. (a) Monitoring point A of the tunnel roof. (b) Monitoring point B of the tunnel wall.

For monitoring point $\mathrm{B}$ in the sidewall, the principal stress directions adjustment process is different from monitoring point $\mathrm{A}$, but it shows some similar characteristics. The major and minor principal stress axes ahead of the tunnel face tend to intersect the excavation surface of the tunnel at angles ranging from $30^{\circ}$ to $60^{\circ}$, with the intermediate principal stress axis almost parallel to the excavation surface (approximately normal to the tunnel axis). In addition, the principal stress directions will adjust themselves dramatically when the tunnel face is $10-12 \mathrm{~m}$ (approximately equal to the tunnel diameter) away from the reference section. When the tunnel face approaches $\mathrm{WF}=60 \mathrm{~m}$, the monitoring points and the working face are located at the same cross-section of the tunnel. The three-dimensional space relationship between the principal stress orientation and the excavation surface, which is beneficial to analysis of excavation stability near the working face, as shown in Figure 7, with schematic diagrams of the principal stress orientation and the tunnel boundary.

\section{Stress State Change of Sequential Tunnel Advancement}

The research above shows that the direction of the principal stress will change at different degrees during tunnel excavation. However, there are only a few reports on the effect of principal stress axis rotation on the stress state ahead of the tunnel face. Here, the stress triaxiality $R_{\sigma}$ and the Rod parameter $\mu_{\sigma}$ are introduced, which are regularly used to feature the stress states of metal materials. In early fracture mechanics, Sih [18] presented the theory that the location with minimum strain energy density is always the location with smaller deformation energy density and larger dilation energy density where brittle rupture readily begins. Based on

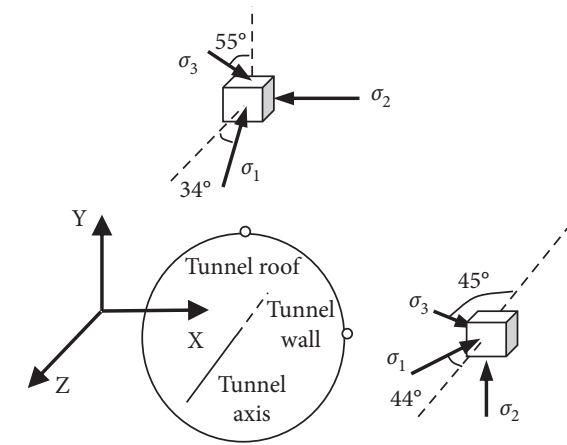

FIGURE 7: Schematic diagram of principal stresses orientation of monitoring points at $\mathrm{WF}=60 \mathrm{~m}$.

Sih's theory, Rice and Tracey [19] defined the expression of stress triaxiality $R_{\sigma}$. Rice believed that the mixed-mode crack extends along the direction of maximum stress triaxiality, which agrees with the type I fracture toughness testing results. In the 1990s, Bao and Wierzbicki [20] and Bao [21] demonstrated that the value of stress triaxiality can reflect the stress state of the material in various force conditions.

The stress triaxiality $R_{\sigma}$ and the Rod parameter $\mu_{\sigma}$ are defined in equations (3) and (4), and Table 2 lists the values of $R_{\sigma}$ and $\mu_{\sigma}$ that represent different stress states from triaxial tension to triaxial compression. $R_{\sigma}$ decreases gradually as the stress state changes from tension to compression. The material is under tension and subject to tensile failure if $R_{\sigma}$ is positive, and the degree of tension increases as $R_{\sigma}$ increases, and vice versa. However, there is no correspondent relationship between the rod parameter and stress state. Therefore, the stress triaxiality $R_{\sigma}$ is relatively better for reflecting the stress state: 
TABLe 2: $R_{\sigma}$ and $\mu_{\sigma}$ under different stress states.

\begin{tabular}{lccccc}
\hline \multirow{2}{*}{ Stress state } & \multicolumn{3}{c}{ Principal stress } & \multirow{2}{*}{$R_{\sigma}$} & $\mu_{\sigma}$ \\
& $\sigma_{1}$ & $\sigma_{2}$ & $\sigma_{3}$ & & \\
\hline Unequal triaxial tension & $\sigma$ & $\sigma$ & $0.5 \sigma$ & 1.67 & 1 \\
Biaxial tension & $\sigma$ & $\sigma$ & 0 & 0.67 & 1 \\
Simple tension & $\sigma$ & 0 & 0 & 0.33 & -1 \\
Pure shear & $\sigma$ & 0 & $-\sigma$ & 0 & 0 \\
Uniaxial compression & 0 & 0 & $-\sigma$ & -0.33 & 1 \\
Biaxial compression & 0 & $-\sigma$ & $-\sigma$ & -0.67 & -1 \\
Unequal triaxial compression & $-0.5 \sigma$ & $-\sigma$ & $-\sigma$ & -1.67 & -1 \\
\hline
\end{tabular}

$$
\begin{aligned}
& R_{\sigma}=\frac{\sqrt{2}\left(\sigma_{1}+\sigma_{2}+\sigma_{3}\right)}{3 \sqrt{\left(\sigma_{1}-\sigma_{2}\right)^{2}+\left(\sigma_{2}-\sigma_{3}\right)^{2}+\left(\sigma_{3}-\sigma_{1}\right)^{2}}}, \\
& \mu_{\sigma}=\frac{2 \sigma_{2}-\sigma_{1}-\sigma_{3}}{\sigma_{1}-\sigma_{3}} .
\end{aligned}
$$

The stress triaxiality $R_{\sigma}$ is the ratio of average normal stress $I_{1} / 3$ and the equivalent shear stress $\sqrt{J_{2}}$, where $I_{1}$ is the first stress invariant and $J_{2}$ is the second deviatoric stress invariant. Figure 8 shows the change curves of $\sigma_{1}, \sigma_{2}, \sigma_{3}$, $I_{1} / 3, \sqrt{J_{2}}$, and $R_{\sigma}$ of the monitoring points as the tunnel face advances. The stress path of monitoring point $\mathrm{A}$ is shown generally as $I_{1} / 3$ decreases and $\sqrt{J_{2}}$ increases, and the stress state of the tunnel roof changes from triaxial compression to biaxial or uniaxial compression. This is the same for monitoring point $\mathrm{B}$ in the tunnel wall.

Careful observation of the 46-60 m (Figure 8(a)) or $48-60 \mathrm{~m}$ (Figure 8(b)) cyclical footage shows that the principal stress values of the monitoring points undergo little change and $I_{1} / 3$ is nearly unchanged at the beginning of the excavation process. The stress concentration begins to occur when the tunnel face is $4-6 \mathrm{~m}$ from the reference section and reaches a peak value as the tunnel face arrives at the reference section. However, during this process (46-60 $\mathrm{m}$ or $48-60 \mathrm{~m}$ cyclical footage), $R_{\sigma}$ and $\sqrt{J_{2}}$ increase rapidly, as shown in Figure 8, and the principal stress axes experience dramatic rotation, as shown in Figure 6.

Obviously, the stress state influenced by the change in magnitudes of the principal stresses can be expressed using stress parameters (e.g., $I_{1} / 3, \sigma_{1}, \sigma_{2}$, and $\sigma_{3}$ ). To determine how the stress state changes with the principal stress axis rotation, the stress increment as a result of only the principal stress axes rotation is analyzed in this paper. A two-dimensional stress state $\sigma$ is analyzed for simplification, as written in equation (5), where $\sigma_{1}$ and $\sigma_{2}$ denote the major and minor principal stress, respectively. It is assumed that $\sigma_{1}$ and $\sigma_{2}$ are constant and the principal stress axes rotate a certain angle $\theta$. The new stress state $\sigma^{\prime}$ after the principal stress axes rotate is written as equation (6), and the relationship between $\sigma$ and $\sigma^{\prime}$ as equation (7), where $Q=\left[\begin{array}{cc}\cos \theta & -\sin \theta \\ \sin \theta & \cos \theta\end{array}\right]$ is the coordinate transformation matrix. The stress increment $d \sigma^{\prime}$ due to the principal stress axis rotation in the new principal stress space is written as equation (8), and the stress increment $d \sigma$ (transformed from $\left.d \sigma^{\prime}\right)$ in the original principal stress space is written as equation (9):

$$
\begin{aligned}
\sigma & =\left[\begin{array}{cc}
\sigma_{1} & 0 \\
0 & \sigma_{2}
\end{array}\right], \\
\sigma^{\prime} & =\left[\begin{array}{cc}
\sigma_{1}^{\prime} & 0 \\
0 & \sigma_{2}^{\prime}
\end{array}\right], \\
\sigma^{\prime} & =Q \sigma Q^{T}, \\
d \sigma^{\prime} & =d\left(Q \sigma Q^{T}\right)=d(Q) \sigma Q^{T}+Q d \sigma Q^{T}+Q \sigma d Q^{T}, \\
d \sigma & =Q^{T} d \sigma^{\prime} Q=\left[\begin{array}{cc}
0 & \left(\sigma_{1}-\sigma_{2}\right) d \theta \\
\left(\sigma_{1}-\sigma_{2}\right) d \theta & 0
\end{array}\right] .
\end{aligned}
$$

Equation (9) shows that the stress increments due to the principal stress axis rotation are mainly influenced by the deviatoric stresses and the rotation angle of the principal stress axes, and the shear stress component of $\left(\sigma_{1}-\sigma_{2}\right) d \theta$ explains that the principal stress axes rotation can result in an increase of $\sqrt{J_{2}}$. Thus, $\sqrt{J_{2}}$ can be considered to be closely related to the stress state change of rock mass due to the principal stress axes rotation, and the reason $R_{\sigma}$ shares similar change laws with $\sqrt{J_{2}}$ and with dramatic change between $46-60 \mathrm{~m}$ or $48-60 \mathrm{~m}$ cyclical footage in Figure 8 can be explained. It is clear from equation (3) that $R_{\sigma}$ denotes the stress state variation induced by the interaction of $I_{1} / 3$ and $\sqrt{J_{2}}$ and can represent the stress state change due to both the variation of magnitude and orientation of the stress-field tensor.

According to the curve of $R_{\sigma}$ with the tunnel face advancing in Figure 8, the stress state change during tunnel excavation can be roughly divided into four stages. In Stage $\mathrm{I}$, at $0-46 \mathrm{~m}$ or $0-48 \mathrm{~m}$ cyclical footage, $R_{\sigma}$ decreases gradually from the initial value of approximately -4.2 , indicating a slight adjustment due to the tunnel excavation. In Stage II, at $46-60 \mathrm{~m}$ or $48-60 \mathrm{~m}$ cyclical footage, $R_{\sigma}$ increases quickly to approximately -1.67 mainly due to the principal stress axes rotation and the stress concentration. In Stage III, at $60-70 \mathrm{~m}$ cyclical footage, $R_{\sigma}$ increases to approximately -0.67 due to the stress release and the principal stress axis rotation as a result of the tunnel face passing through the reference section. Then, $R_{\sigma}$ is approximately unchanged in Stage IV at $70-100 \mathrm{~m}$ cyclical footage.

Figure 9 shows the nephogram of $R_{\sigma}$ when the tunnel face moves towards the reference section. According to the $R_{\sigma}$ curves in Figure 8 and the physical meaning of the stress state values in Table 2 , some characteristic values are selected as thresholds for evaluating the degree and characteristics of stress disturbance. Therefore, the stress disturbance zone of the excavated tunnel is divided into approximately two sections, as shown in Figure 9. One section is near the tunnel surface with $R_{\sigma}>-1.67$, similar to an even hollow cylinder and extended approximately half of a tunnel diameter (0.5D) from the tunnel boundary into the rock mass. This section suffers from quick stress release, strong stress direction 


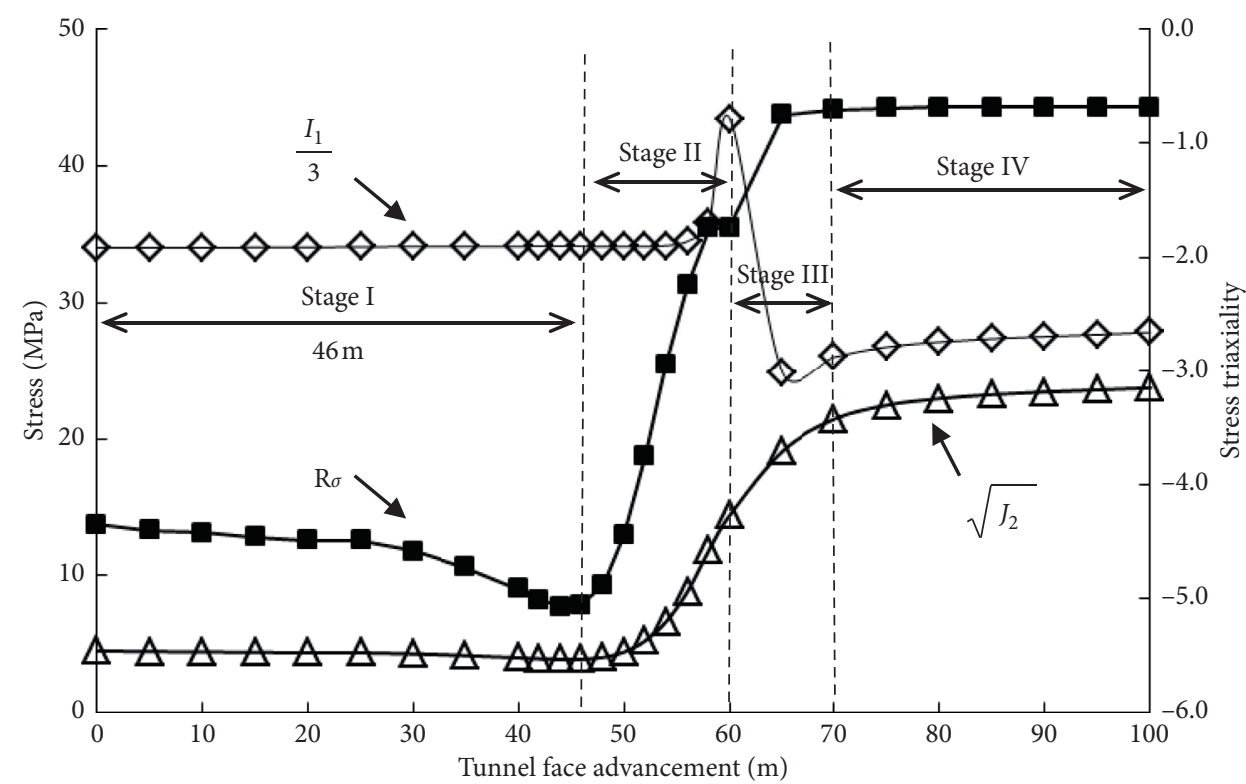

(a)

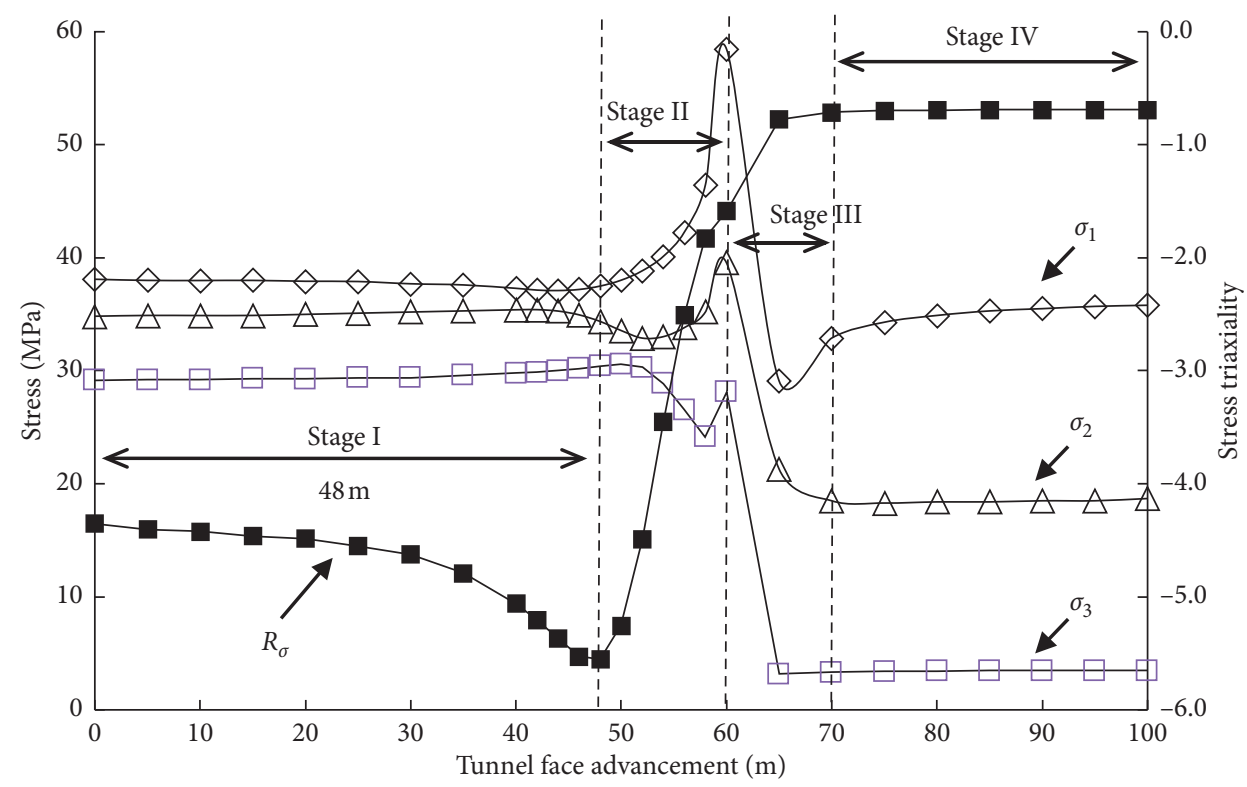

(b)

Figure 8: The curves of $\sigma_{1}, \sigma_{2}, \sigma_{3}, I_{1} / 3, \sqrt{J_{2}}$, and $R_{\sigma}$ with tunnel face advancing (Stage I: stress adjustment; Stage II: principal stress axis rotation and stress concentration; Stage III: stress release and principal stress axis rotation; Stage IV: stress redistribution).
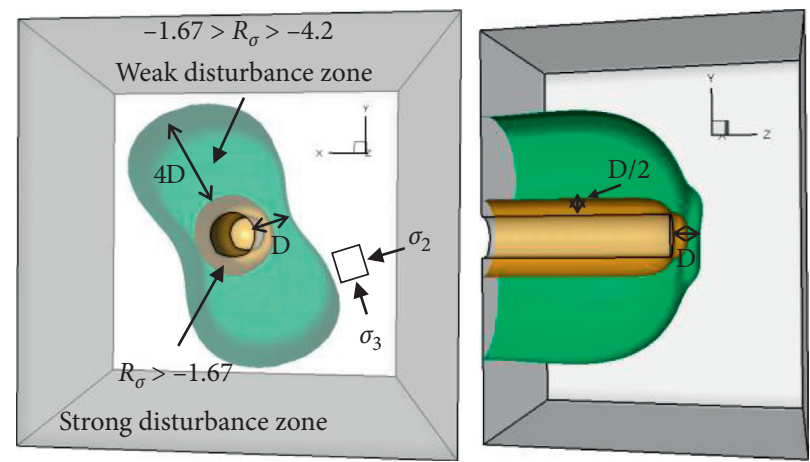

Figure 9: Nephogram of stress triaxiality as the tunnel face approaches the reference section. 
rotation, and the stress state variations from triaxial compression to biaxial or uniaxial compression due to the tunnel excavation. Another section is far from the tunnel surface, with $-1.67>R_{\sigma}>-4.2$. The distribution range of this section is 1-4 times as large as the tunnel diameter (1-4D) along the radial direction and approximately as large as the tunnel diameter (1D) ahead of the tunnel face, and its space form may be affected by the primary in situ stress field. This zone is disturbed weakly, where the stress magnitude and stress directions after excavation have little change compared with the initial in situ condition, and the stress state changes from unequal triaxial compression to hydrostatic loading condition. The distribution of the strong stress disturbance zone nearly coincides with that of the damage zone of tunnel excavation in some literature $[6,10]$, which indicates that the stress triaxiality can reasonably be used to describe the change of stress state and the stress disturbance zone of the excavated tunnel.

\section{Conclusions}

The study on the principal stress orientation and the stress state changes during the advancement of the tunnel face in the diversion tunnels of the Jinping II Hydropower Station presents some elementary conclusions on stress disturbance characteristics and mechanisms:

(1) The pole diagram can describe the rotation of the principal stress axes as the tunnel face advances and the analysis result shows that the orientation adjustments of principal stresses in different positions near the tunnel boundary have some common characteristics. The minor and major principal stresses ahead of the tunnel face will rotate to intersect the excavation surface of the tunnel at angles ranging from $30^{\circ}$ to $60^{\circ}$, with the intermediate principal stress nearly parallel to the excavation surface (approximately normal to the tunnel axis). In addition, the principal stress directions will adjust themselves dramatically at approximately 10-12 m (approximately equal to the tunnel diameter) ahead of the tunnel face, as the tunnel face moves forward.

(2) The stress triaxiality, which is commonly used to indicate the deformation and damage of metal materials, is introduced to describe the stress state changes of the primary in situ stress field. The stress triaxiality is found to represent the stress state change due to the variation of both magnitude and orientation of the stress-field tensor. According to the physical meaning and the change law of stress triaxiality, the stress disturbance during tunnel excavation can be divided into four stages.

(3) In terms of the disturbance mechanism and spatial distribution of the stress triaxiality, the stress disturbance zone is divided into the strong disturbance zone and the weak disturbance zone with different disturbance characteristics. The strong disturbance zone extends approximately half the tunnel diameter from the tunnel boundary into the rock mass, which suffers from quick stress release, strong stress direction rotation, and stress state variations from triaxial compression to biaxial or uniaxial compression due to the tunnel excavation.

\section{Data Availability}

The data used to support the findings of this study are included within the article.

\section{Conflicts of Interest}

The authors declare that they have no conflicts of interest.

\section{Acknowledgments}

The authors wish to acknowledge the financial supports of the National Basic Research Program of China (no. 2015CB057905) and State Key Laboratory of Geotechnical Mechanics and Engineering (no. Z018022).

\section{References}

[1] J. Seki, K. Noda, E. Washizawa, T. Suzuki, and K. Nishino, "Effect of bench length on stability of tunnel face," in Proceedings of the International Congress on Tunneling And Ground Conditions, M. E. Abdel-Salam, Ed., A.A. Balkema, Cairo, Egypt, pp. 531-542, April 1994.

[2] C. D. Martin, "Seventeenth Canadian Geotechnical Colloquium: the effect of cohesion loss and stress path on brittle rock strength," Canadian Geotechnical Journal, vol. 34, no. 5, pp. 698-725, 1997.

[3] E. Eberhardt, D. Stead, M. J. Reeves, and C. Connors, "Design of tabular excavations in foliated rock: an integrated numerical modeling approach," Geotechnical and Geological Engineering, vol. 15, no. 1, pp. 47-85, 1997.

[4] L. H. I. Meyer, D. Stead, and J. S. Coggan, “Three dimensional modelling of the effects of high horizontal stress on underground excavation stability," in Proceedings of the Ninth International Congress on Rock Mechanics, G. Vouille and P. Berest, Eds., A. A. Balkema, Paris, France, pp. 411-416, August 1999.

[5] B. Shen, O. Stephansson, M. Rinne et al., "modeling of rock fracturing and permeability change in excavation-damaged zones," International Journal of Geomechanics, vol. 11, no. 4, pp. 302-313, 2011.

[6] F. Yamashi, C.-Q. Zhang, L. Shao-Jun, S.-Li Qiu, and C.-S. Zhang, Dynamic Design Method for Deep Tunnels in Hard Rock, Science Press, Beijing, China, 2013.

[7] R. S. Read, "20 years of excavation response studies at AECL's Underground Research Laboratory," International Journal of Rock Mechanics \& Mining Sciences, vol. 8, no. 41, pp. 12511275, 2004.

[8] J. Martino and N. Chandler, "Excavation-induced damage studies at the underground research laboratory," International Journal of Rock Mechanics and Mining Sciences, vol. 8, no. 41, pp. 1413-1426, 2004.

[9] J. C. Andersson, C. D. Martin, and H. Stille, “The Äspö Pillar Stability Experiment: Part II-Rock mass response to coupled excavation-induced and thermal-induced stresses," International Journal of Rock Mechanics and Mining Sciences, vol. 46, no. 5, pp. 879-895, 2009. 
[10] S. Emsley, O. Olsson, L. Stenberg et al., "ZEDEX: a study of damage and disturbance from tunnel excavation by blasting and tunnel boring," in The Excavation Damaged Zon-an International Perspective, C. Fairhurst and B. Damjanac, Eds., pp. 4-14, Canadian Nuclear Society, Manitoba, Canada, 1997.

[11] Q. Jiang, X.-T. Feng, T.-B. Xiang, and G.-S. Su, "Rockburst characteristics and numerical simulation based on a new energy index: a case study of a tunnel at 2,500 m depth," Bulletin of Engineering Geology and the Environment, vol. 69, no. 3, pp. 381-388, 2010.

[12] N. Su, C. Zhang, X. Chen et al., "Monitoring and characteristics study of stress evolution of surrounding rock during deep tunnel excavation," Chinese Journal of Rock Mechanics and Engineering, vol. 30, no. 9, pp. 1729-1737, 2011.

[13] R. K. S. Wong and J. R. F. Arthur, "Sand sheared by stresses with cyclic variations in direction," Géotechnique, vol. 36, no. 2, pp. 215-226, 1986.

[14] L. Han and P. Dayakar, "Experiment investigation on principle stress rotation in Kaolin clay," Journal Of Geotechnical And Geoenvironmental Engineering, ASCE, vol. 131, no. 5, pp. 633-642, 2005.

[15] B. J. Carter, "Size and stress gradient effects on fracture around cavities," Rock Mechanics and Rock Engineering, vol. 25, no. 3, pp. 167-186, 1992.

[16] L. N. Germanovich and A. V. Dyskin, "Fracture mechanisms and instability of openings in compression," International Journal of Rock Mechanics and Mining Sciences, vol. 37, no. 12, pp. 263-284, 2000.

[17] E. Eberhardt, "Numerical modelling of three-dimension stress rotation ahead of an advancing tunnel face," International Journal of Rock Mechanics and Mining Sciences, vol. 38, no. 4, pp. 499-518, 2001.

[18] G. C. Sih, "Strain-energy-density factor applied to mixed mode crack problems," International Journal of Fracture, vol. 10, no. 3, pp. 305-321, 1974.

[19] J. R. Rice and D. M. Tracey, On the Ductile Enlargement of Ductile Materials Incorporating Void Nucleation, Growth and Interaction, Ph.D. thesis, Brown University, Providence, RI, USA, 1975.

[20] Y. Bao and T. Wierzbicki, "On fracture locus in the equivalent strain and stress triaxiality space," International Journal of Mechanical Sciences, vol. 46, no. 1, pp. 81-98, 2004.

[21] Y. Bao, "Dependence of ductile crack formation in tensile tests on stress triaxiality, stress and strain ratios," Engineering Fracture Mechanics, vol. 72, no. 4, pp. 505-522, 2005. 